Article

\title{
The Relationship between Circulating Acetate and Human Insulin Resistance before and after Weight Loss in the DiOGenes Study
}

\author{
Manuel A. González Hernández ${ }^{1}\left(\mathbb{D}\right.$, Emanuel E. Canfora ${ }^{1}{ }^{\circledR}$, Kenneth Pasmans ${ }^{1}$, A. Astrup ${ }^{2}$, \\ W. H. M. Saris ${ }^{1}$ and Ellen E. Blaak ${ }^{1, *(D)}$ \\ 1 Department of Human Biology, NUTRIM School of Nutrition and Translational Research in Metabolism, \\ Maastricht University Medical Centre+, Universiteitssingel 50, P.O. Box 616, 6229 ER Maastricht, \\ The Netherlands; m.gonzalezhernandez@maastrichtuniversity.nl (M.A.G.H.); \\ emanuel.canfora@maastrichtuniversity.nl (E.E.C.); k.pasmans@maastrichtuniversity.nl (K.P.); \\ w.saris@maastrichtuniversity.nl (W.H.M.S.) \\ 2 Department of Human Nutrition, University of Copenhagen, 1171 Copenhagen, Denmark; ast@nexs.ku.dk \\ * Correspondence: e.blaak@maastrichtuniversity.nl; Tel. +31433881503
}

Received: 9 January 2020; Accepted: 26 January 2020; Published: 28 January 2020 updates

\begin{abstract}
Microbially-produced acetate has been reported to beneficially affect metabolic health through effects on satiety, energy expenditure, insulin sensitivity, and substrate utilization. Here, we investigate the association between sex-specific concentrations of acetate and insulin sensitivity/resistance indices (Homeostatic Model Assessment of Insulin Resistance (HOMA-IR), circulating insulin and Matsuda Index) in the Diet, Obesity and Genes (DiOGenes) Dietary study at baseline and after a low-calorie diet (LCD, $800 \mathrm{kcal} / \mathrm{d}$ ). In this analysis, 692 subjects (Body Mass Index $>27 \mathrm{~kg} / \mathrm{m}^{2}$ ) were included, who underwent an LCD for 8 weeks. Linear mixed models were performed, which were adjusted for mean acetate concentration, center (random factor), age, weight loss, and fat-free mass (FFM). At baseline, no associations between plasma acetate and insulin sensitivity/resistance indices were found. We found a slight positive association between changes in acetate and changes in HOMA-IR $(\operatorname{std} \beta 0.130, p=0.033)$ in women, but not in $\operatorname{men}(\operatorname{std} \beta-0.072$, $p=0.310$ ) independently of age, weight loss and FFM. We were not able to confirm previously reported associations between acetate and insulin sensitivity in this large European cohort. The mechanisms behind the sex-specific relationship between LCD-induced changes in acetate and insulin sensitivity require further study.
\end{abstract}

Keywords: short chain fatty acids; obesity; insulin resistance; weight loss

\section{Introduction}

Microbially-derived acetate has been shown to play an important role in substrate and energy metabolism [1]. In rodents fed high-fat diets, beneficial effects on insulin sensitivity [2] and increased white adipose tissue browning have been reported [3]. However, rodent data are not entirely consistent since intragastric acetate infusions in rats have resulted in hyperphagia and energy retention [4].

In humans, rectal acetate infusions have been shown to increase plasma peptide YY (PYY) and glucagon-like peptide-1 in hyperinsulinaemic overweight women [5]. Furthermore, acute distal colonic acetate infusions and short chain fatty acids (SCFA) mixtures high in acetate decreased whole-body lipolysis, increased fasting fat oxidation, resting energy expenditure, and PYY secretion in overweight men [6,7]. Additionally, circulating acetate was positively associated with increased fat oxidation and energy expenditure [7]. Recently, a study reported that acetate produced in the distal colon contributes significantly to systemic acetate concentrations in men [8]. In line with this, cross-sectional analyses in 
patients with obesity have shown positive associations between high circulating acetate and insulin sensitivity indices $[9,10]$. In women, plasma acetate correlated negatively with fasting and postprandial insulin concentrations [9]. In morbidly obese subjects, acetate correlated negatively with Homeostatic Model Assessment of Insulin Resistance (HOMA-IR) [10]. Notably, a resistant starch supplementation ( $30 \mathrm{~g} / \mathrm{d}$ for 4 weeks) in healthy subjects increased acetate uptake in muscle and adipose tissue and improved insulin sensitivity (as measured by hyperinsulinemic-euglycemic clamp) [11].

Here, we assess the association of (changes in) circulating acetate and insulin sensitivity/resistance indices (HOMA-IR, circulating insulin and Matsuda Index) at baseline and after an eight-week low calorie diet (LCD) in male and female overweight/obese subjects of the European Diet, Obesity and Genes (DiOGenes) Dietary study. Due to the fact that microbial composition and functionality, as well as their impact on insulin sensitivity, may differ in overweight males and females, we stratified our analysis for sex [12].

\section{Materials and Methods}

\subsection{Study Design}

The DiOGenes project is a multicenter, randomized, controlled dietary intervention study in 8 European countries. In total, 938 overweight or obese, nondiabetic adults, free of cardiovascular disease (age 18-65 years, body mass index (BMI) $27-45 \mathrm{~kg} / \mathrm{m}^{2}$ and fasting blood glucose concentrations $<6.1 \mathrm{mmol} / \mathrm{L}$ ) were recruited. Subjects using prescription medication or suffering from diseases or conditions that might influence the outcome of the study were excluded. Of special interest were diseases that influenced body weight regulation (e.g., malabsorption, untreated hypo/hyperthyroidism, eating disorders, systemic use of steroids) and obesity-related cardiovascular risk factors (heart disease, systolic and diastolic blood pressures $\geq 160 / 100 \mathrm{mmHg}$, blood glucose $>6.1 \mathrm{mmolL}^{-1}$, blood cholesterol $>7 \mathrm{mmolL}^{-1}$, blood triglycerides $>3 \mathrm{mmolL}^{-1}$ ). More details on recruitment, inclusion, and exclusion criteria and study design are described elsewhere [13].

The Medical Ethical Committees of the respective countries approved the study protocol, which followed the Helsinki II regulations. The study was registered with ClinicalTrials.gov, number NCT00390637. Succinctly, the study consisted of two phases. In this report, we focus on the baseline characterization of the overweight/obese individuals as well as the weight-loss phase in which individuals with BMI $>27 \mathrm{~kg} / \mathrm{m}^{2}$ were assigned to lose weight following an LCD for 8 weeks. The LCD provided 3.3 MJ/d (800 kcal/d) using Modifast products (Nutrition et Santé, France, area code 31451), with a macronutrient composition of $15-20 \%$ of total energy from fat, 35-40\% from protein, and $45-50 \%$ from carbohydrate. In addition, subjects could also eat up to $400 \mathrm{~g}$ of vegetables, providing a total of 3.3 to $4.2 \mathrm{MJ} / \mathrm{d}(800$ to $1000 \mathrm{kcal} / \mathrm{d})$.

\subsection{Study Population}

We included 692 volunteers (441 women, 251 men) from whom plasma metabolomics (including acetate) were available before and after the LCD. Volunteers with BMI $>27 \mathrm{~kg} / \mathrm{m}^{2}$ were recruited in eight different research centers across Europe: Maastricht (the Netherlands), Copenhagen (Denmark), Cambridge (United Kingdom), Heraklion (Greece), Potsdam (Germany), Pamplona (Spain), Sofia (Bulgaria), and Prague (the Czech Republic). All subjects provided written informed consent before enrollment into the study.

\subsection{Anthropometry and Blood Sampling}

Anthropometry and blood samples were collected after fasting (10 hours) at baseline (clinical investigation day 1, CID1) and after weight loss at the end of the LCD period (CID2). In this report, we included the following parameters: anthropometry (body weight, BMI, and fat-free mass (FFM)). FFM was assessed by multifrequency bioimpedance (QuadScan 4000, Bodystat, Douglas, United Kingdom) [13]. Additionally, glucose, free fatty acids (FFA) (automatic spectrophotometric enzymatic 
techniques) and insulin were measured from fasting samples [13]. Insulin concentrations were measured by a colorimetric assay (Ortho-Clinical Diagnostics, Johnson \& Johnson, Birkerød, Denmark) [14]. Homeostatic Model Assessment of Insulin Resistance (HOMA-IR) and insulin sensitivity (Matsuda index) were calculated. HOMA-IR was calculated as follows: HOMA-IR $=\left(\right.$ glucose $(\mathrm{mmol} / \mathrm{L}){ }^{*}$ insulin $(\mu \mathrm{U} / \mathrm{mL}) / 22.5)$, using fasting values [15]. Matsuda index was calculated as follows: (10,000/square root of (fasting glucose $\mathrm{x}$ fasting insulin) $\mathrm{x}$ (mean glucose $\mathrm{x}$ mean insulin during Oral glucose tolerance test (OGTT))) [16]. BMI was calculated by dividing the mass in $\mathrm{kg}$ by squared height. FFM was obtained from bioimpedance analysis. Acetate, acetoacetate, and 3-OH-butyrate were quantified in serum from nuclear magnetic resonance (NMR) spectra, as reported previously in detail [17]. Physical activity was measured before and after LCD by means of the Baecke questionnaire [13].

\subsection{Statistical Analysis}

The normality of data was assessed with the Kolmogorov-Smirnov procedure and histogram and variables that were not normally distributed were Ln-transformed. Repeated measures ANOVA with Bonferroni correction was conducted to investigate sex, time, and sex-time effects as a result of the LCD phase. A linear mixed model (LMM) was used to determine the relationship between (changes in) acetate and (changes in) insulin sensitivity/resistance parameters at baseline and after the LCD. In the first model, besides (changes in) acetate and (changes in) fasting insulin, HOMA-IR or Matsuda index, mean acetate was added. Subsequently, age (Model 2), (change in) weight (Model 3), and (change in) FFM (Model 4) were added as covariates. In all models, the center was included as a random factor.

\section{Results}

\subsection{Cross-Sectional Analysis at Baseline}

Acetate showed significantly higher levels in men as compared to women at baseline (1.35 \pm 1.39 vs. $1.13 \pm 0.97 \mathrm{mmol} / \mathrm{L}$, respectively, see Table 1). There were no differences in BMI between males and females. Furthermore, fasting insulin, HOMA-IR, fasting glucose, body weight and FFM were higher in males, whilst the Matsuda index, FFA, and ketone bodies were lower (see Table 1). There were no relationships between acetate and fasting insulin, HOMA-IR, and Matsuda Index in males as well as in females.

\subsection{Weight Loss by LCD}

In response to the $L C D$, acetate levels increased in both men and women $(1.35 \pm 1.39$ to $1.45 \pm$ 1.16 and $1.13 \pm 0.97$ to $1.25 \pm 1.03 \mathrm{mmol} / \mathrm{L}$, respectively, Table 1$)$, but did not differ between sexes $(p=0.852)$. Weight reduction increased insulin sensitivity, as assessed by Matsuda $(p=0.002)$ and decreased HOMA-IR $(p=0.004)$ and fasting insulin $(p=0.001)$, with more pronounced improvements in males as compared to females. Additionally, FFA slightly increased as a result of weight loss with a more pronounced increase in males as compared to females (Table 1). Ketone bodies (acetoacetate and 3-OH-butyrate) showed an increase while acetate/3-OH-butyrate and acetate/acetoacetate ratios decreased after LCD; however, sex-time interactions were not significant. Physical activity (sports and work indexes) did not change after LCD. Leisure activity differed (sex and time); however, sex-time interaction was not significant.

We observed a slight positive relationship between LCD-induced changes in acetate concentrations and changes in HOMA-IR ( $\operatorname{std} \beta 0.130, p=0.033$, Table 2 ) and with changes in fasting insulin concentrations ( $\operatorname{std} \beta 0.119, p=0.051)$ in women, but not in $\operatorname{men}(\operatorname{std} \beta-0.072, p=0.310$ and $\operatorname{std} \beta-0.066$, $p=0.359$, respectively; data not shown). Subsequently, the relationship between (changes in) acetate and HOMA-IR did not change after adjustment for age and changes in body weight as well as changes in FFM (Table 2). A similar result was seen for (changes in) fasting insulin (Table 3). The relationship between changes in acetate and Matsuda index did not reach statistical significance (data not shown). 
Table 1. Characteristics of participants before and after low calorie diet (LCD) intervention.

\begin{tabular}{|c|c|c|c|c|c|c|c|}
\hline & \multicolumn{2}{|c|}{ Men } & \multicolumn{2}{|c|}{ Women } & \multirow{2}{*}{ Effect-Sex } & \multirow{2}{*}{ Time } & \multirow{2}{*}{ Time $\times$ Sex } \\
\hline & Baseline & After LCD & Baseline & After LCD & & & \\
\hline$n$ & 175 & 175 & 303 & 303 & & & \\
\hline Age $(y r)$ & $42 \pm 6$ & $42 \pm 6$ & $41 \pm 6$ & $41 \pm 6$ & 0 & & 1 \\
\hline Acetate $(\mathrm{mmol} / \mathrm{L})$ & $1.36 \pm 1.54$ & $1.41 \pm 1.25$ & $1.12 \pm 1.03$ & $1.18 \pm 1.04$ & 0.000 & 0.016 & 0.672 \\
\hline HOMA index & $3.86 \pm 2.35$ & $2.18 \pm 2.23$ & $2.93 \pm 3.0$ & $2.00 \pm 2.53$ & 0.000 & 0.000 & 0.004 \\
\hline Matsuda index & $4.10 \pm 2.50$ & $7.16 \pm 3.8$ & $5.67 \pm 3.50$ & $7.55 \pm 3.70$ & 0.000 & 0.000 & 0.002 \\
\hline Insulin $(\mu \mathrm{U} / \mathrm{mL})$ & $13.8 \pm 7.6$ & $8.1 \pm 5.3$ & $11.14 \pm 11.14$ & $8.18 \pm 9.32$ & 0.000 & 0.000 & 0.001 \\
\hline Glucose (mmol/L) & $5.3 \pm 0.6$ & $5.0 \pm 0.5$ & $5.0 \pm 0.6$ & $4.8 \pm 0.3$ & 0.000 & 0.000 & 0.457 \\
\hline FFA (micromol/L) & $528 \pm 190$ & $634 \pm 204$ & $675 \pm 263$ & $746 \pm 213$ & 0.000 & 0.000 & 0.176 \\
\hline Acetoacetate (mmol/L) & $0.06 \pm 0.04$ & $0.23 \pm 0.30$ & $0.09 \pm 0.07$ & $0.25 \pm 0.30$ & 0.000 & 0.000 & 0.376 \\
\hline 3-OH-butyrate $(\mathrm{mmol} / \mathrm{L})$ & $0.35 \pm 0.30$ & $1.52 \pm 2.00$ & $0.56 \pm 0.52$ & $1.69 \pm 1.94$ & 0.000 & 0.000 & 0.133 \\
\hline Acetate/3-OH-butyrate ratio & $5.80 \pm 8$ & $2.08 \pm 3$ & $3.50 \pm 4.90$ & $1.40 \pm 2.04$ & 0.000 & 0.000 & 0.415 \\
\hline Acetate/Acetoacetate ratio & $26 \pm 29$ & $12 \pm 16$ & $18 \pm 21$ & $9 \pm 10$ & 0.000 & 0.000 & 0.787 \\
\hline Body weight $(\mathrm{kg})$ & $111.8 \pm 17.5$ & $99.0 \pm 15.9$ & $96.8 \pm 16.5$ & $86.6 \pm 15$ & 0.000 & 0.000 & 0.702 \\
\hline BMI $\left(\mathrm{kg} / \mathrm{m}^{2}\right)$ & $35 \pm 4.8$ & $31 \pm 4.4$ & $35.2 \pm 5.1$ & $31.4 \pm 4.6$ & 0.259 & 0.000 & 0.657 \\
\hline Fat-free mass $(\mathrm{kg})$ & $73.4 \pm 9.9$ & $69.8 \pm 8.7$ & $53.4 \pm 8.1$ & $51 \pm 8$ & 0.000 & 0.000 & 0.990 \\
\hline \multicolumn{8}{|l|}{ Baecke Questionnaire scores } \\
\hline Leisure index & $2.6 \pm 0.7$ & $2.8 \pm 0.6$ & $2.70 \pm 0.7$ & $3.07 \pm 0.6$ & 0.000 & 0.001 & 0.569 \\
\hline Sports index & $2.6 \pm 0.4$ & $2.6 \pm 0.4$ & $2.6 \pm 0.5$ & $2.7 \pm 0.4$ & 0.620 & 0.675 & 0.310 \\
\hline Work index & $2.7 \pm 0.4$ & $2.8 \pm 0.4$ & $2.7 \pm 0.4$ & $2.7 \pm 0.3$ & 0.087 & 0.670 & 0.980 \\
\hline
\end{tabular}

Repeated measures ANOVA. First $p$-value reported corresponds to sex effect. Second $p$-value corresponds to the time effect and third $p$-value corresponds to the sex-time effect. Data expressed as mean and standard deviation. Abbreviations: low-calorie diet (LCD), Homeostatic Model Assessment of Insulin Resistance (HOMA-IR), BMI (Body Mass Index) free fatty acids (FFA). 
Table 2. Determinants of changes in HOMA-IR in participants during weight loss.

\begin{tabular}{cccccc}
\hline \multirow{2}{*}{ Model } & Parameter & \multicolumn{2}{c}{ Females } & \multicolumn{2}{c}{ Males } \\
\cline { 3 - 5 } & & $\begin{array}{c}\text { Std B, Confidence } \\
\text { Interval }\end{array}$ & $p$-Value & $\begin{array}{c}\text { Std B, Confidence } \\
\text { Interval }\end{array}$ & $p$-Value \\
\hline 1 & $\Delta$-Acetate Mean acetate & $0.111(0.013$ to 0.209$)$ & 0.027 & $-0.098(-0.224$ to 0.027$)$ & 0.123 \\
2 & Model $1+$ Age & $0.125(0.027$ to 0.223$)$ & 0.013 & $-0.101(-0.227$ to 0.025$)$ & 0.115 \\
3 & Model $2+\Delta$-Weight & $0.120(0.022$ to 0.218$)$ & 0.017 & $-0.069(-0.189$ to 0.051$)$ & 0.259 \\
4 & Model 3 $+\Delta$-Fat-free mass & $0.130(0.010$ to 0.249$)$ & 0.033 & $-0.072(-0.211$ to 0.068$)$ & 0.310 \\
\hline
\end{tabular}

Linear mixed model was adjusted for age, weight, and fat-free mass. All models were adjusted for center as a random factor (coefficients not shown). Acetate concentration (independent factor) and HOMA-IR as dependent factors. Statistically significant $p$-values are in bold. Valid cases $n=302$ females, 175 males.

Table 3. Determinants of changes in fasting insulin in participants during weight loss.

\begin{tabular}{|c|c|c|c|c|c|}
\hline \multirow{2}{*}{ Model } & \multirow{2}{*}{ Parameter } & \multicolumn{2}{|l|}{ Females } & \multicolumn{2}{|l|}{ Males } \\
\hline & & $\begin{array}{c}\text { Std } B \text {, Confidence } \\
\text { Interval }\end{array}$ & $p$-Value & $\begin{array}{c}\text { Std } B, \text { Confidence } \\
\text { Interval }\end{array}$ & $p$-Value \\
\hline 1 & $\Delta$-Acetate Mean acetate & $0.132(0.034$ to 0.231$)$ & 0.009 & $-0.085(-0.212$ to 0.042$)$ & 0.190 \\
\hline 2 & Model $1+$ Age & $0.140(0.042$ to 0.238$)$ & 0.005 & $-0.089(-0.217$ to 0.038$)$ & 0.168 \\
\hline 3 & Model $2+\Delta$-Weight & $0.132(0.035$ to 0.229$)$ & 0.008 & $-0.064(-0.188$ to 0.059$)$ & 0.306 \\
\hline 4 & Model $3+\Delta$-Fat-free mass & $0.119(-0.001$ to 0.238$)$ & 0.051 & $-0.066(-0.207$ to 0.075$)$ & 0.359 \\
\hline
\end{tabular}

Linear mixed model was adjusted for age, weight, and fat-free mass. All models were adjusted for center as a random factor (coefficients not shown). Acetate concentration (independent factor) and HOMA-IR as dependent factors. Statistically significant $p$ values are in bold. Valid cases $n=295$ females, 175 males.

\section{Discussion}

In the present study, we could not confirm previously reported positive associations between acetate and insulin sensitivity and metabolic health parameters in a cross-sectional analysis at baseline. LCD-induced weight loss increased insulin sensitivity more in men than in women. Surprisingly, we found a slight positive association between LCD-induced changes in acetate and changes in HOMA-IR and fasting insulin concentrations in overweight/obese women, but not in men, which was independent of age and changes in body composition.

As previously described, cross-sectional studies showed negative associations between acetate and fasting insulin in obese women [9]. Similarly, in morbidly obese subjects, a negative association with HOMA-IR and a positive association with insulin sensitivity were observed [10]. Furthermore, acute distal colonic acetate infusions increased fat oxidation and improved metabolic profile in overweight/obese men [6,7]. Surprisingly, we observed a slight positive relationship between the LCD-induced change in circulating acetate and change in HOMA-IR and fasting insulin in females, but not in males. In line with these results on differential associations between males and females, a previous DiOGenes analysis by Stroeve et al. [17], suggested a sex-specific modulatory role of baseline acetate in energy metabolism, since they reported a negative association with LCD-induced BMI change in morbidly obese females (std $\beta-0.23$ ), but not in males. Furthermore, a previous analysis in the DiOGenes study showed that despite the fact that hepatic insulin resistance was lower in females as compared to males, there was a more pronounced worsening of blood lipid profile with the progression of hepatic insulin resistance in females, but not in males [18]. In interpreting our results, it is important to note that acetate kinetics (acetate absorption in the colon, hepatic uptake and acetate clearance), and turnover (production/utilization) are intricate processes that are influenced by the interplay of gut microbial fermentation, lipogenesis, lipid oxidation and ketogenesis [19]. With respect to the insulinemic profile, hyperinsulinemia may affect acetate metabolism, possibly via an alteration in endogenous and exogenous acetate metabolism [20]. In addition, a caloric restriction may augment hepatic ketogenesis via an overproduction of acetyl-coA coming from increased lipid utilization [21] and increased ketogenesis may also elevate acetate production [22]. 
The exact mechanisms behind the sex-specific relationship of acetate and HOMA-IR may relate to sex hormones affecting processes such as microbial metabolism, hepatic lipid metabolism, and ketogenesis. Notably, in our study, most women were in the premenopausal state; however, data on the hormone status was not available. Ketone bodies increased after the LCD with no differences between males and females. In addition, acetate/3-OH-butyrate and acetate/acetoacetate ratios decreased after LCD, which may suggest that the contribution of acetate from sources other than hepatic ketogenesis has probably not increased after LCD [23]. Thus, the discrepancy of our findings on the relationship between acetate and insulin resistance as well as the sexual dimorphism in this relationship remains to be elucidated, taking into account the complex acetate kinetics. Finally, other SCFA (propionate and butyrate) may be of importance for insulin sensitivity, as we and other publications have reported [24-28]. Unfortunately, these metabolites were not included in the NMR measurements and we focused on acetate, the most abundant SCFA in the colonic lumen and systemic circulation.

The major strength of our study is the availability of HOMA-IR and a 5-point oral glucose tolerance test (including insulin concentrations for calculation of the Matsuda index) in a large and well-characterized cohort, which made additional adjustment for confounding factors feasible. A limitation of our study is the lack of information on acetate kinetics and colonic acetate that may contribute to circulating acetate concentrations. Of note, in the current study, we measured plasma acetate concentrations using NMR methodology, of which validation has been previously described $[17,29,30]$. Although the absolute concentrations of acetate may differ as compared to previous studies measured with LC-MS or GC-MS [6-9,25,31,32], high correlations have been reported between metabolites measured with both LC-MS and NMR [33].

In conclusion, the results of this large pan-European study (692 volunteers) showed no relationship between acetate and markers of insulin sensitivity. Furthermore, a small positive association between LCD-induced changes in acetate and HOMA-IR and fasting insulin (explaining 1-2\% of the variance in HOMA-IR or fasting insulin) was shown in females and not in males. Future studies should aim to elucidate the underlying mechanisms and physiological significance.

Author Contributions: Conceptualization, E.E.C.; Data curation, A.A. and W.H.M.S.; Formal analysis, M.A.G.H. and K.P.; Supervision, E.E.C. and E.E.B.; Writing—original draft, M.A.G.H.; Writing—review \& editing, M.A.G.H., E.E.C. and E.E.B. All authors have read and agreed to the published version of the manuscript.

Funding: European Commission, Food Quality and Safety Priority of the Sixth Framework Program (FP6_2005-513946) supported the study and MAG's salary was paid by a grant from Consejo Nacional de Ciencia y Tecnología (CONACYT).

Acknowledgments: The DiOGenes project is part of the Sixth Framework Programme for Research and Technological Development of the European Union (2005-2009).

Conflicts of Interest: The authors declare no conflict of interest.

\section{References}

1. Canfora:, E.E.; Blaak, E.E. Acetate: A diet-derived key metabolite in energy metabolism: Good or bad in context of obesity and glucose homeostasis? Curr. Opin. Clin. Nutr. Metabolic Care 2017, 20, 477-483. [CrossRef]

2. den Besten, G.; Bleeker, A.; Gerding, A.; van Eunen, K.; Havinga, R.; van Dijk, T.H.; Oosterveer, M.H.; Jonker, J.W.; Groen, A.K.; Reijngoud, D.J.; et al. Short-Chain Fatty Acids Protect Against High-Fat Diet-Induced Obesity via a PPARgamma-Dependent Switch From Lipogenesis to Fat Oxidation. Diabetes 2015, 64, 2398-2408. [CrossRef]

3. Sahuri-Arisoylu, M.; Brody, L.P.; Parkinson, J.R.; Parkes, H.; Navaratnam, N.; Miller, A.D.; Thomas, E.L.; Frost, G.; Bell, J.D. Reprogramming of hepatic fat accumulation and 'browning' of adipose tissue by the short-chain fatty acid acetate. Int. J. Obes. (Lond.) 2016, 40, 955-963. [CrossRef]

4. Perry, R.J.; Peng, L.; Barry, N.A.; Cline, G.W.; Zhang, D.; Cardone, R.L.; Petersen, K.F.; Kibbey, R.G.; Goodman, A.L.; Shulman, G.I. Acetate mediates a microbiome-brain- $\beta$-cell axis to promote metabolic syndrome. Nature 2016, 534, 213-217. [CrossRef] 
5. Freeland, K.R.; Wolever, T.M. Acute effects of intravenous and rectal acetate on glucagon-like peptide-1, peptide YY, ghrelin, adiponectin and tumour necrosis factor-alpha. Br. J. Nutr. 2010, 103, 460-466. [CrossRef]

6. van der Beek, C.M.; Canfora, E.E.; Lenaerts, K.; Troost, F.J.; Damink, S.W.; Holst, J.J.; Masclee, A.A.; Dejong, C.H.; Blaak, E.E. Distal, not proximal, colonic acetate infusions promote fat oxidation and improve metabolic markers in overweight/obese men. Clin. Sci. (Lond.) 2016, 130, 2073-2082. [CrossRef]

7. Canfora, E.E.; van der Beek, C.M.; Jocken, J.W.E.; Goossens, G.H.; Holst, J.J.; Olde Damink, S.W.M.; Lenaerts, K.; Dejong, C.H.C.; Blaak, E.E. Colonic infusions of short-chain fatty acid mixtures promote energy metabolism in overweight/obese men: A randomized crossover trial. Sci. Rep. 2017, 7, 2360. [CrossRef]

8. Neis, E.P.J.G.; van Eijk, H.M.H.; Lenaerts, K.; Olde Damink, S.W.M.; Blaak, E.E.; Dejong, C.H.C.; Rensen, S.S. Distal versus proximal intestinal short-chain fatty acid release in man. Gut 2018. [CrossRef]

9. Layden, B.T.; Yalamanchi, S.K.; Wolever, T.M.; Dunaif, A.; Lowe, W.L., Jr. Negative association of acetate with visceral adipose tissue and insulin levels. Diabetes Metab. Syndr. Obes. 2012, 5, 49-55. [CrossRef]

10. Moreno-Navarrete, J.M.; Serino, M.; Blasco-Baque, V.; Azalbert, V.; Barton, R.H.; Cardellini, M.; Latorre, J.; Ortega, F.; Sabater-Masdeu, M.; Burcelin, R.; et al. Gut Microbiota Interacts with Markers of Adipose Tissue Browning, Insulin Action and Plasma Acetate in Morbid Obesity. Mol. Nutr. Food Res. 2018, 62. [CrossRef]

11. Robertson, M.D.; Bickerton, A.S.; Dennis, A.L.; Vidal, H.; Frayn, K.N. Insulin-sensitizing effects of dietary resistant starch and effects on skeletal muscle and adipose tissue metabolism. Am. J. Clin. Nutr. 2005, 82, 559-567. [CrossRef]

12. Most, J.; Goossens, G.H.; Reijnders, D.; Canfora, E.E.; Penders, J.; Blaak, E.E. Gut microbiota composition strongly correlates to peripheral insulin sensitivity in obese men but not in women. Benef Microbes 2017, 8, 557-562. [CrossRef]

13. Larsen, T.M.; Dalskov, S.; van Baak, M.; Jebb, S.; Kafatos, A.; Pfeiffer, A.; Martinez, J.A.; Handjieva-Darlenska, T.; Kunesova, M.; Holst, C.; et al. The Diet, Obesity and Genes (Diogenes) Dietary Study in eight European countries-A comprehensive design for long-term intervention. Obes. Rev. Off. J. Int. Assoc. Study Obes. 2010, 11, 76-91. [CrossRef]

14. Goyenechea, E.; Holst, C.; van Baak, M.A.; Saris, W.H.M.; Jebb, S.; Kafatos, A.; Pfeiffer, A.; Handjiev, S.; Hlavaty, P.; Stender, S.; et al. Effects of different protein content and glycaemic index of ad libitum diets on diabetes risk factors in overweight adults: The DIOGenes multicentre, randomized, dietary intervention trial. Diabetes/Metabolism Res. Rev. 2011, 27, 705-716. [CrossRef]

15. Matthews, D.R.; Hosker, J.P.; Rudenski, A.S.; Naylor, B.A.; Treacher, D.F.; Turner, R.C. Homeostasis model assessment: Insulin resistance and beta-cell function from fasting plasma glucose and insulin concentrations in man. Diabetologia 1985, 28, 412-419. [CrossRef]

16. Matsuda, M.; DeFronzo, R.A. Insulin sensitivity indices obtained from oral glucose tolerance testing: Comparison with the euglycemic insulin clamp. Diabetes Care 1999, 22, 1462-1470. [CrossRef]

17. Stroeve, J.H.M.; Saccenti, E.; Bouwman, J.; Dane, A.; Strassburg, K.; Vervoort, J.; Hankemeier, T.; Astrup, A.; Smilde, A.K.; van Ommen, B.; et al. Weight loss predictability by plasma metabolic signatures in adults with obesity and morbid obesity of the DiOGenes study. Obesity 2016, 24, 379-388. [CrossRef]

18. van der Kolk, B.W.; Vogelzangs, N.; Jocken, J.W.E.; Valsesia, A.; Hankemeier, T.; Astrup, A.; Saris, W.H.M.; Arts, I.C.W.; van Greevenbroek, M.M.J.; Blaak, E.E.; et al. Plasma lipid profiling of tissue-specific insulin resistance in human obesity. Int. J. Obes. 2019, 43, 989-998. [CrossRef]

19. Piloquet, H.; Ferchaud-Roucher, V.; Duengler, F.; Zair, Y.; Maugere, P.; Krempf, M. Insulin effects on acetate metabolism. Am. J. Physiol. Endocrinol. Metab. 2003, 285, E561-E565. [CrossRef]

20. Fernandes, J.; Vogt, J.; Wolever, T.M.S. Kinetic model of acetate metabolism in healthy and hyperinsulinaemic humans. Eur. J. Clin. Nutr. 2014, 68, 1067-1071. [CrossRef]

21. Knowles, S.E.; Jarrett, I.G.; Filsell, O.H.; Ballard, F.J. Production and utilization of acetate in mammals. Biochem. J. 1974, 142, 401-411. [CrossRef]

22. Leighton, F.; Bergseth, S.; Rørtveit, T.; Christiansen, E.N.; Bremer, J. Free acetate production by rat hepatocytes during peroxisomal fatty acid and dicarboxylic acid oxidation. J. Biol. Chem. 1989, 264, 10347-10350.

23. Seufert, C.D.; Mewes, W.; Soeling, H.D. Effect of long-term starvation on acetate and ketone body metabolism in obese patients. Eur. J. Clin. Investig. 1984, 14, 163-170. [CrossRef]

24. Sanna, S.; van Zuydam, N.R.; Mahajan, A.; Kurilshikov, A.; Vich Vila, A.; Võsa, U.; Mujagic, Z.; Masclee, A.A.M.; Jonkers, D.M.A.E.; Oosting, M.; et al. Causal relationships among the gut microbiome, short-chain fatty acids and metabolic diseases. Nat. Genet. 2019, 51, 600-605. [CrossRef] [PubMed] 
25. Müller, M.; Hernández, M.A.G.; Goossens, G.H.; Reijnders, D.; Holst, J.J.; Jocken, J.W.E.; van Eijk, H.; Canfora, E.E.; Blaak, E.E. Circulating but not faecal short-chain fatty acids are related to insulin sensitivity, lipolysis and GLP-1 concentrations in humans. Sci. Rep. 2019, 9, 12515. [CrossRef] [PubMed]

26. Todesco, T.; Rao, A.V.; Bosello, O.; Jenkins, D.J. Propionate lowers blood glucose and alters lipid metabolism in healthy subjects. Am. J. Clin. Nutr. 1991, 54, 860-865. [CrossRef] [PubMed]

27. Wolever, T.M.; Brighenti, F.; Royall, D.; Jenkins, A.L.; Jenkins, D.J. Effect of rectal infusion of short chain fatty acids in human subjects. Am. J. Gastroenterol. 1989, 84, 1027-1033.

28. Gao, Z.; Yin, J.; Zhang, J.; Ward, R.E.; Martin, R.J.; Lefevre, M.; Cefalu, W.T.; Ye, J. Butyrate Improves Insulin Sensitivity and Increases Energy Expenditure in Mice. Diabetes 2009, 58, 1509. [CrossRef]

29. Emwas, A.H.; Roy, R.; McKay, R.T.; Tenori, L.; Saccenti, E.; Gowda, G.A.N.; Raftery, D.; Alahmari, F.; Jaremko, L.; Jaremko, M.; et al. NMR Spectroscopy for Metabolomics Research. Metabolites 2019, 9, 123. [CrossRef]

30. Dona, A.C.; Kyriakides, M.; Scott, F.; Shephard, E.A.; Varshavi, D.; Veselkov, K.; Everett, J.R. A guide to the identification of metabolites in NMR-based metabonomics/metabolomics experiments. Comput. Struct. Biotechnol. J. 2016, 14, 135-153. [CrossRef]

31. Canfora, E.E.; van der Beek, C.M.; Hermes, G.D.A.; Goossens, G.H.; Jocken, J.W.E.; Holst, J.J.; van Eijk, H.M.; Venema, K.; Smidt, H.; Zoetendal, E.G.; et al. Supplementation of Diet With Galacto-oligosaccharides Increases Bifidobacteria, but Not Insulin Sensitivity, in Obese Prediabetic Individuals. Gastroenterology 2017, 153, 87-97. [CrossRef] [PubMed]

32. Gathungu, R.M.; Kautz, R.; Kristal, B.S.; Bird, S.S.; Vouros, P. The integration of LC-MS and NMR for the analysis of low molecular weight trace analytes in complex matrices. Mass Spectrom. Rev. 2020, 39, 35-54. [CrossRef] [PubMed]

33. Lanza, I.R.; Zhang, S.; Ward, L.E.; Karakelides, H.; Raftery, D.; Nair, K.S. Quantitative Metabolomics by 1H-NMR and LC-MS/MS Confirms Altered Metabolic Pathways in Diabetes. PLoS ONE 2010, 5, e10538. [CrossRef] [PubMed]

(C) 2020 by the authors. Licensee MDPI, Basel, Switzerland. This article is an open access article distributed under the terms and conditions of the Creative Commons Attribution (CC BY) license (http://creativecommons.org/licenses/by/4.0/). 